\title{
LA LESIÓN DE LOS DERECHOS FUNDAMENTALES EN EL PROCEDIMIENTO DE TUTELA LABORAL \\ Comentario a un fallo del Juzgado de Letras del Trabajo de Copiapó del \\ 15 de septiembre de 2008, RUC 08-4-0001305-6
}

\section{LUIS ALEJANDRo Silva IRARRÁZAVAL}

\section{INTRODUCCIÓN}

La eficacia horizontal de los derechos fundamentales se decide en la aplicación judicial de las normas que los garantizan. Pero la adecuada protección jurisdiccional de esta clase de derechos no se mide exclusivamente por la justicia material de la decisión, sino también por el argumento que la sostiene. Es este segundo criterio el que usaremos para comentar esta sentencia, la primera dictada en el nuevo procedimiento de tutela laboral ${ }^{1}$.

Esta primera sentencia dictada por el Juzgado de Letras del Trabajo de Copiapó, ofrece varios aspectos dignos de ser comentados. Nosotros hemos escogido uno, que consiste en la valoración del supuesto de hecho "lesión de derechos fundamentales", contenido en diversas normas que la sentencia aplica. Como podremos apreciar, el juez pondera de manera distinta el mismo supuesto, incurriendo en una contradicción lógica.

Nos interesa centrar la atención en el hecho seńalado en la demanda como lesivo de la garantía constitucional del artículo 19 No 5 . Este hecho es invocado en la demanda para negar la validez de la prueba presentada por la demandada (artículo 453 No 5 del Código del Trabajo). El mismo hecho es alegado por la demandante para obtener una sentencia definitiva favorable a sus pretensiones (artículos 485 y 489 del Código del Trabajo).

\footnotetext{
Abogado. Profesor de Derecho Constitucional de la Universidad de los Andes y Doctor en Derecho por la misma Universidad. Correo electrónico: 1silva@uandes.cl

Fecha de recepción: 23 de abril de 2009.

Fecha de aprobación: 4 de junio de 2009.

1 El nuevo procedimiento de tutela laboral se inserta en una reforma más amplia del procedimiento laboral, incorporada por la ley 20.087(D.O., 3 de enero de 2005), que sustituyó el Capítulo V del Código del Trabajo. Sobre la materia pueden consultarse WALTer, Rodolfo y Lanata, Gabriela (2007). Régimen legal del nuevo proceso laboral chileno. Estudios de las modificaciones introducidas por las leyes $N^{\circ}$ s 20.022, 20.023 y 20.087, $2^{\text {a }}$ edición, Santiago: LexisNexis; Ugarte, José Luis (2007). El nuevo derecho del trabajo, Santiago: LexisNexis; Silva, Rodrigo (2006). Manual de procedimiento laboral. Análisis de la Ley $N^{\circ} 20.087$, Santiago: Editorial Jurídica de Chile; Gamonal, Sergio (2007). El procedimiento de tutela de derechos laborales, Santiago: LexisNexis.
} 
También es utilizado por el juez para alterar el onus probandi (artículo 493) y para descartar la posibilidad de un acuerdo entre las partes (artículo 495). De este modo, el juez se ve en la necesidad de juzgar si hubo lesión del derecho fundamental a la intimidad aplicando el supuesto del artículo 453 No 5; del artículo 458 inciso $1^{\circ}$; del artículo 495 inciso $2^{\circ}$ y del artículo 493. En la sentencia que vamos a analizar, el mismo hecho se pondera varias veces (tantas cuantos supuestos hay) con resultados distintos en un caso.

\section{1) Resumen Del CASO}

La demandante fue contratada por la Sociedad de Profesionales Kronos - una empresa de fiscalización técnica- como ITO administrativo en la construcción del Gran Casino de Copiapó, a cargo de la empresa Salfa Construcciones. Con ocasión de su trabajo, la demandante conoció un e-mail privado del jefe de proyectos de la empresa Kronos, que entregó a través del messenger a una amiga suya, trabajadora de la empresa Salfa. Este acto fue descubierto por el jefe inmediato de la actora al encontrar el respaldo del diálogo electrónico en la carpeta Mis Documentos, ubicada en el escritorio del computador al que varios usuarios de la oficina tenían acceso. En virtud del reglamento interno de la empresa, que regula, entre otras materias, el deber de lealtad que deben guardar sus trabajadores, fue despedida. Entonces, la afectada demandó a través del nuevo procedimiento de tutela laboral la declaración del despido como vulneratorio de su derecho a la inviolabilidad de todo tipo de comunicaciones privadas y el pago de las correspondientes indemnizaciones.

\section{2) LOS SUPUESTOS DE HECHO}

En el considerando $3^{\circ}$, valorando los hechos a la luz del artículo 495 del Código del Trabajo, el juez asumió la existencia de una vulneración de los derechos que se invocaron en la demanda. Por esta razón no hubo conciliación ni una invitación para llegar a acuerdo mediante ofrecimientos económicos. Sin ninguna justificación el juez estableció que existió una vulneración del derecho fundamental de la demandante que, mientras no fuera reconocido por el demandado, le impedía autorizar acuerdo alguno entre las partes. Es evidente el prejuicio del juez: "Se llamó a las partes a conciliación, la que no fructificó en razón de la negativa de la demandada a aceptar cualquier reconocimiento de una vulneración de los derechos que se invocaron como conculcados. Luego ante el mandato consagrado en el artículo 495 (...) este juzgador en particular, prefirió no invitar a la realización de ofrecimientos económicos". (Considerando $3^{\circ}$ ). 
En el considerando $6^{\circ}$ letra a) el juez desestimó la solicitud de la actora, de aplicar el artículo 453 No 5 del Código del Trabajo para negar validez a la prueba presentada por la demandada. La negativa del juez de debió a que no pudo formarse el convencimiento de que hubiera sido obtenida a través de medios ilícitos o actos que implicaran violación de derechos fundamentales. Esto significa que el acceso al respaldo del diálogo electrónico en el cual constaba el envío del e-mail que motivó el despido, no vulneró el derecho de la actora a la inviolabilidad de todo tipo de comunicaciones privadas. "Al respecto no fue posible, a través de la prueba rendida, formarse convicción (...) que el conocimiento de las conversaciones privadas (...) se OBTUVO a través de medios ilícitos o a través de actos que impliquen violación de derechos fundamentales. (...) Con lo anterior, al no haber quedado acreditado el supuesto de hecho -obtención de una vulneración tan evidente- que fundaría una exclusión valorativa de la prueba ingresada por la demandada (...), necesariamente deberá desestimarse la solicitud esgrimida de que no se diera valor probatorio a dicho documento" 2 .

En el considerando $7^{\circ}$, el juez analizó si los antecedentes contenidos en la demanda satisfacían el supuesto de hecho del artículo 493, a fin de establecer si procedía alterar el onus probandi. De nuevo la atención se centró en el hecho de haber accedido un tercero al respaldo del diálogo electrónico guardado sin clave en uno de los computadores de la oficina. Dijo el juez: "Del análisis de la prueba (...), este juzgador tiene por establecido, que existen antecedentes suficientes, para al menos estimar a priori, que eventualmente el despido (...) pudiese estar fundado en la utilización de información de carácter privado" 3 . En otras palabras, se consideró que había indicios suficientes de que la obtención de la información vulneró el derecho a la inviolabilidad de todo tipo de comunicación privada.

Por último, en el considerando $8^{\circ}$, el juez ponderó el hecho a la luz del supuesto del artículo 485 inciso $3^{\circ}$. Es el considerando más largo y denso de la sentencia. En él asentó al comienzo los supuestos de su razonamiento: que en el presente caso se trata de una colisión de derechos fundamentales del trabajador y del empleador, y que el método para resolver la colisión es la ponderación de derechos. A lo largo del argumento el juez examinó, esencialmente, la proporcionalidad que hubo entre el acto del empleador tendente a resguardar sus derechos (propiedad y libertad económica), que consistió en acceder al respaldo de la conversación electrónica, y la limitación que dicho acto supuso para los derechos del trabajador

\footnotetext{
2 Mayúsculas en el original. La frase entre guiones es una interpolación del juez: la ley no exige que la vulneración sea "evidente".

3 El estándar fijado por el juez para estimar que hay "indicios suficientes" es, en verdad, bajo: "...al menos estimar a priori, que eventualmente (...) pudiese..." [cursivas nuestras].
} 
(concretamente, la inviolabilidad de las comunicaciones privadas). Después de un detallado análisis, el juez concluyó que no existió proporción alguna, porque la posibilidad de acceder a información privada debía estar prevista en el reglamento interno de la empresa (y no lo estaba) y porque, dado el contenido del e-mail y la oportunidad en que se entregó, el acto de la demandante no significó para los derechos del empleador ningún riesgo. Luego, la actuación del demandado vulneró el derecho fundamental de la actora. "Con lo razonado, este juez (...) estima que el demandado no ha dado suficientes fundamentos de las medidas adoptadas y su proporcionalidad, por lo que necesariamente deberá instarse por la protección del derecho fundamental del trabajador". (Considerando $8^{\circ}$ letra c).

\section{3) COMENTARIo}

En la sentencia que analizamos, la constatación judicial de la existencia de una lesión a los derechos fundamentales parece responder a parámetros distintos, según el supuesto de hecho que se trata de aplicar. El mismo hecho que es indicado como lesivo del mismo derecho, resulta serlo solo en algunos supuestos. El haber accedido al respaldo del diálogo electrónico significó una lesión de derechos fundamentales para efectos del artículo 495 inciso $2^{\circ}$ (abstención de autorizar acuerdos), para efectos del artículo 493 (alteración del onus probandi) y para efectos del artículo 485 inciso $3^{\circ}$ (ejercicio de las facultades legales del empleador); pero no para efectos del artículo 453 No 5 (obtención de la prueba presentada en juicio).

Esta circunstancia solo puede explicarse racionalmente suponiendo que existen parámetros distintos para valorar el hecho que se reputa lesivo. Pero exceptuando el supuesto del artículo 493, en el que el estándar de valoración es evidentemente más amplio (porque solo exige "indicios suficientes"), no encontramos fundamento alguno en la ley que justifique una distinta valoración del hecho.

Somos de la opinión que la sentencia incurre en una contradicción al valorar el mismo hecho como lesivo en un caso y no en otro. Es como si dijera: "No hay pruebas de que el conocimiento de las conversaciones privadas de la actora se hayan obtenido a través de actos que impliquen violación de derechos fundamentales (concretamente, la inviolabilidad de las comunicaciones privadas), pero los actos del demandado tendentes a proteger sus derechos constituyeron un límite desproporcionado a los derechos fundamentales de la actora (concretamente, la inviolabilidad de las comunicaciones privadas)." Es una contradicción porque, en este caso, el acto por el cual se obtuvo la prueba es el mismo acto por el cual el demandado buscó proteger sus derechos, y no es lógico que el mismo acto respecto del mismo derecho sea, simultáneamente, lesivo y no lesivo. 
Creemos que esta contradicción nace de una confusión del juez, que se manifiesta claramente en la parte resolutiva de la sentencia. Dice: "Que el despido (...) ha sido consecuencia directa de la vulneración de la garantía de inviolabilidad de toda forma de comunicación privada (...). Dicho despido, en consecuencia, es vulneratorio de derechos fundamentales". En la primera oración de la cita la vulneración del derecho fundamental es causa del despido; en cambio, en la segunda oración, es consecuencia del despido. En la demanda no se invoca otro derecho que el garantizado por el artículo 19 No 5 de la Constitución, por lo que entendemos que el derecho fundamental vulnerado por el despido es el mismo que se invoca como causa del despido. Sin embargo, resulta absurdo pensar que el despido pueda afectar el derecho a la inviolabilidad de todo tipo de comunicación privada. Podrá afectar otros derechos fundamentales, pero no vemos cómo podría afectar la intimidad. El juez confunde la causa del despido con la consecuencia del despido, confusión que origina la contradicción que señalábamos anteriormente. $\mathrm{O}$ bien hay vulneración del derecho a la intimidad y entonces la prueba carece de valor, o bien no existe tal vulneración pero el despido es desproporcionado a la falta de la empleada. Lo que no puede ser es que el acceso a las comunicaciones privadas de la actora no haya vulnerado el derecho a la intimidad en cuanto medio de obtener la prueba, pero sí en cuanto causa del despido; como tampoco puede ser que la vulneración de la intimidad haya sido la causa y la consecuencia del despido.

\section{CONCLUSIÓN}

Es un error aplicar el mismo supuesto de hecho, en una misma causa, con criterios de valoración distintos. La sentencia comentada incurre en este error, sentando un mal precedente en orden a una adecuada protección de los derechos fundamentales. En efecto, al valorar de manera distinta el mismo supuesto de hecho, introduce un factor de incertidumbre respecto de los parámetros del juez para juzgar cuándo efectivamente se han vulnerado los derechos fundamentales. Con ello, el margen de la discrecionalidad judicial para determinar el alcance de los derechos fundamentales (que de por sí es amplio) crece hasta perderse en la arbitrariedad y poner en riesgo la identidad misma de esos derechos.

\section{BibLiografía}

Gamonal, Sergio (2007). El procedimiento de tutela de derechos laborales, Santiago. LexisNexis.

Silva, Rodrigo (2006). Manual de procedimiento laboral. Análisis de la Ley $N^{\circ}$ 20.087, Santiago: Editorial Jurídica de Chile. 
Ugarte, José Luis (2007). El nuevo derecho del trabajo, Santiago: LexisNexis.

Walter, Rodolfo y Lanata, Gabriela (2007). Régimen legal del nuevo proceso laboral chileno. Estudios de las modificaciones introducidas por las leyes $N^{\circ}$ s 20.022, 20.023 y 20.087, 2a edición, Santiago: LexisNexis. 